\title{
Familial vesicoureteral reflux
}

INSERM

\section{Source}

INSERM. (1999). Orphanet: an online rare disease and orphan drug data base. Familial vesicoureteral reflux. ORPHA:289365

Familial vesicoureteral reflux is a rare, non-syndromic urogenital tract malformation characterized by the familial occurrence of retrog rade flow of urine from the bladder into the ureter and sometimes the kidneys. Patients may be asymptomatic or may present with recurrent, sometimes febrile, urinary tract infections that, in case of acute pyelonephritis, may lead to serious complications (renal scarring, hypertension, renal failure). Spontaneous resolution of the disorder is possible. 